\title{
Biological Control of Botrytis cinerea in Cyclamen with Ulocladium atrum and Gliocladium roseum Under Commercial Growing Conditions
}

\author{
J. Köhl, M. Gerlagh, B. H. De Haas, and M. C. Krijger
}

DLO Research Institute for Plant Protection (IPO-DLO), P.O. Box 9060, 6700 GW Wageningen, the Netherlands. Accepted for publication 6 March 1998.

\section{ABSTRACT}

Köhl, J., Gerlagh, M., De Haas, B. H., and Krijger, M. C. 1998. Biological control of Botrytis cinerea in cyclamen with Ulocladium atrum and Gliocladium roseum under commercial growing conditions. Phytopathology 88:568-575.

The effect of treatments with conidial suspensions of Ulocladium atrum and Gliocladium roseum on leaf rot of cyclamen caused by Botrytis cinerea was investigated under commercial greenhouse conditions. Spraying $U$. atrum $\left(1 \times 10^{6}\right.$ conidia per $\left.\mathrm{ml}\right)$ or $G$. roseum $\left(2 \times 10^{6}\right.$ conidia per $\mathrm{ml}$ and $1 \times 10^{7}$ conidia per $\mathrm{ml}$ ) at intervals of 2 to 3 weeks during the production period and spraying $U$. atrum $\left(1 \times 10^{6}\right.$ conidia per $\left.\mathrm{ml}\right)$ at intervals of 4 to 6 weeks resulted in a significant reduction of natural infections of petioles by B. cinerea. U. atrum or G. roseum $\left(1 \times 10^{7}\right.$ conidia per ml) was as effective as the standard fungicide program. $B$. cinerea colonized senesced leaves within the plant canopy and infected adjacent petioles and leaves later. The antagonists colonized senesced leaves and reduced $B$. cinerea development on these leaves. Thus, the inoculum potential on petioles adjacent to necrotic leaf tissues was reduced. The fate of $U$. atrum conidia on surfaces of green cyclamen leaves during a 70-day period after application was studied. The number of conidia per square centimeter of leaf surface remained relatively constant during the entire experiment. Sixty percent of the conidia sampled during the experiments retained the ability to germinate. When green leaves were removed from the plants to induce senescence and subsequently were incubated in a moist chamber, $U$. atrum colonized the dead leaves. Senesced leaves also were colonized by other naturally occurring fungi including $B$. cinerea. On leaves treated with $U$. atrum from all sampling dates, sporulation of $B$. cinerea was significantly less as compared with the untreated control. Our results indicate that early applications of $U$. atrum before canopy closure may be sufficient to achieve commercially satisfactory control of Botrytis leaf rot in cyclamen.

Additional keywords: competition, fungal colonization, gray mold, saprophyte.
Botrytis cinerea Pers. ex Pers. causes leaf rot as one of the major diseases of cyclamen (Cyclamen persicum L.) in the commercial production of potted plants and seeds $(10,20)$. Conidia of the pathogen are produced in necrotic lesions of infected plants or on crop residues. From such sources, conidia are spread through the air of greenhouses. Grower's activities in greenhouses result in a substantial increase in the density of conidia in the air within a greenhouse (6).

Because conidia of $B$. cinerea cannot infect healthy cyclamen leaves (21), the pathogen initially colonizes senescing leaves or necrotic tissues, and produces large numbers of conidia after the plant develops a dense canopy, which increases the relative humidity $(\mathrm{RH})$ within the canopy. Conidial clusters and mycelia of the pathogen can infect healthy tissues of adjacent petioles. Subsequently, the leaf blade can be colonized through the infected petiole. The disease can spread through the entire plant by attacking petioles. This leads to gaps in the plant canopy, which reduce their ornamental value or result in a complete loss of plants.

Control of the greenhouse climate is an important means to reduce the risk of disease epidemics in cyclamen (10). Potted plants are placed on mats, and water is supplied via the mats to avoid wetting above-ground plant parts. However, senescing or dead leaves in contact with the soil surface often are moist enough to allow infection or saprophytic colonization by $B$. cinerea. In addition, once leaves are wet, the relatively low temperature required by cyclamen for growth slows drying. Removal of dead leaves by

Corresponding author: J. Köhl; E-mail address: j.kohl@ipo.dlo.nl

Publication no. P-1998-0423-01R

(C) 1998 The American Phytopathological Society hand reduces the risk of $B$. cinerea infection; however, this procedure is labor intensive. Furthermore, healthy leaves can be injured during handling, and the fresh wounds or enhanced formation of senesced leaves can lead to new infections by $B$. cinerea.

Although fungicides are regularly applied to control $B$. cinerea in crops of cyclamen, there is a need for other controls because fungicide use may be limited in the future by governmental regulations. Second, resistance of $B$. cinerea populations in greenhouses against several fungicides is a common problem $(2,5)$. Benomylresistant strains of $B$. cinerea were found in cyclamen production in the early 1970s (23), and the occurrence of populations resistant to benzimidazoles and dicarboximides (iprodione, procymidone, or vinclozolin) has been reported in Greece and France $(17,19)$. Third, several fungicides, such as iprodione and vinclozolin, can have negative side effects on cyclamen, reducing the yield or the ornamental value of potted plants (8). Finally, plants with visible residues of fungicides on the leaves cannot be marketed.

Antagonistic fungi or bacteria have been reported to suppress $B$. cinerea in several crops (3), including cyclamen. Bollen (1) reported that infections by $B$. cinerea were reduced by naturally occurring Penicillium spp. When these antagonists were eliminated by fungicides such as benomyl, the damage caused by benomyl-resistant $B$. cinerea populations increased after benomyl applications. Iyozumi et al. (9) controlled $B$. cinerea on cyclamen petals in the greenhouse by applications of Serratia marcescens. The same bacterium suppressed sporulation of $B$. cinerea by more than $85 \%$ on leaf blades placed on the soil near the plant base.

The fungal antagonists Gliocladium roseum Bain. and Ulocladium atrum Press were selected for their ability to suppress the colonization of dead tissues of cyclamen and other crops by $B$. cinerea and its subsequent sporulation. $U$. atrum is effective over a broad 
range of temperatures (J. Köhl, unpublished data) and in the open field (14) and survives interruptions in leaf wetness (16). Strains of $G$. roseum have the potential to suppress $B$. cinerea in a range of crops grown in the open field or in greenhouses (22). In bioassays under controlled conditions, G. roseum was more effective than $U$. atrum under continuously moist conditions and moderate temperatures, but was sensitive to low temperatures (J. Köhl, unpublished data) and interruptions in leaf wetness (16). The antagonism of $U$. atrum is most likely based on nutrient competition, whereas antibiotic substances are involved in the antagonism of G. catenulatum (11) and presumably also in the antagonism of G. roseum.

The objective of our study was to test the fungal antagonists $G$. roseum and $U$. atrum for their ability to suppress $B$. cinerea in commercially grown cyclamen crops. Populations of $B$. cinerea in the commercial greenhouse were monitored for fungicide resistance to ensure that the pathogen was sensitive to the fungicides used. In additional trials, the fate of $U$. atrum conidia on green leaves and their ability to colonize such leaves after senescence was investigated in order to optimize timing of the applications of the antagonist and increase the intervals between applications.

\section{MATERIALS AND METHODS}

Inoculum production. Conidia of $U$. atrum isolate 385 , originating from necrotic leaf tips of onions (16), were produced on oat grains in autoclavable spawnbags (type 3LS; Sylvan, Horst, the Netherlands). Oat kernels were moistened in tap water in a vessel overnight (300 g of dry oat kernels and $300 \mathrm{ml}$ of tap water), excess water was drained through a sieve, and the moistened oat kernels were put in a spawnbag. The open end of the bag was inserted into a metal ring, the remaining opening was closed with a cotton plug, and the bag was sealed with autoclavable tape. Bags with the oat kernels were autoclaved twice at $121^{\circ} \mathrm{C}$ for $45 \mathrm{~min}$ at a 24 -h interval. The sterilized oats were inoculated with $0.5 \mathrm{ml}$ of a conidial suspension of $U$. atrum (approximately $1 \times 10^{5}$ conidia per $\mathrm{ml}$ ) and incubated for 28 days at $20^{\circ} \mathrm{C}$ in the dark. Bags were shaken every 2 to 3 days to mix the kernels and to avoid formation of aerial mycelium. Suspensions of conidia of $U$. atrum were prepared by transferring the incubated oat kernels into nylon gauze bags with 1 - by $0.4-\mathrm{mm}$ mesh and agitating these bags for $5 \mathrm{~min}$ in a small washing machine (Nova MW 100; Nova, Maastricht, the Netherlands) in 5 liters of chilled tap water $\left(5^{\circ} \mathrm{C}\right)$ with $0.01 \%$ (vol/vol) Tween 80 . The resulting suspension was filtered through a nylon gauze with $200-\mu \mathrm{m}$ mesh to remove mycelial fragments and oat kernel debris.

G. roseum isolate 1813 , isolated from a potato peel, was cultured in petri dishes $(90 \mathrm{~mm})$ containing $30 \mathrm{ml}$ of oatmeal agar (20 $\mathrm{g}$ of oatmeal, $15 \mathrm{~g}$ of agar, and 1 liter of tap water) for 14 days at $20^{\circ} \mathrm{C}$ in the dark. To obtain conidial suspensions, cultures were flooded with sterile tap water containing $0.01 \%$ (vol/vol) Tween 80. After gently rubbing the surface of the culture with a rubber spatula, the resulting suspension with the conidia was filtered through sterile nylon gauze with a mesh of $200 \mu \mathrm{m}$.

Concentrations of the conidia in the suspensions were determined with the aid of a haemocytometer and adjusted with chilled tap water containing $0.01 \%(\mathrm{vol} / \mathrm{vol})$ Tween 80 to $1 \times 10^{6}$ conidia per $\mathrm{ml}$ for $U$. atrum, and $2 \times 10^{6}$ conidia per $\mathrm{ml}$ (experiment 1 ) or $1 \times 10^{7}$ conidia per ml (experiment 2) for G. roseum. Suspensions were kept at $5^{\circ} \mathrm{C}$ and were applied within 4 to $6 \mathrm{~h}$.

Plants. Cyclamen plants (C. persicum) cv. Super Serie from four lines with different flower color (wine red, lilac, pink, and white with red heart) were used in all experiments. This cultivar has a characteristically compact growth, resulting in a very dense canopy.

Plants were seeded in trays with soil plugs and transferred into individual 8-cm pots containing a commercial potting soil ("Lentse" special cyclamen mixture; Lentse Potgrond B.V., Lent, the Netherlands) at $\approx 10$ weeks after sowing (three-leaf stage). For $\approx 6$ weeks, the plants were held on trays. Subsequently, they were placed on tables with mats at wider spacing; spacing was increased further after $\approx 6$ weeks on the tables in order to avoid touching of leaves of different plants. Flowering plants were considered marketable $\approx 30$ weeks after sowing when they had 50 to 55 leaves. In the first experiment, treatments were initiated with 19-week-old plants, 3 weeks after the plants were placed on the tables. In the second experiment, treatments were initiated with 16-week-old plants still on the trays. For two other experiments conducted in an experimental greenhouse at Wageningen, the Netherlands, 20 week-old plants, each with an average of 15 leaves, were used.

Growing conditions. Experiments were conducted in a 3,000- $\mathrm{m}^{2}$ commercial greenhouse at Twello, the Netherlands, in which cyclamen and several other ornamental crops were produced. Minimum temperatures were set at $14^{\circ} \mathrm{C}$ during daytime and $16^{\circ} \mathrm{C}$ during nighttime. The $\mathrm{RH}$ was set at $80 \%$. On warm or rainy days, temperature or RH may have exceeded the set values due to insufficient capacity of climate control by ventilation and screening.

Treatments. In the first experiment, four treatments were arranged in a randomized complete block design, with each treatment replicated four times. Two blocks were located on each of two opposite tables. In the second experiment, all blocks were located on the same table. There were no buffers between treatments. In the first experiment, each replicate started with 63 plants placed in nine rows of 7 plants, of which the central 25 plants were assessed for disease development. In the second experiment, five treatments were arranged in a randomized complete block design, with each treatment replicated four times. Each replication consisted of 24 plants in four rows of six plants. Plants were numbered to allow disease assessments in time for each individual plant. In both experiments, plants within each block belonged to the same lines with the same flower color, but flower colors between blocks differed.

Treatments consisted of spraying the cyclamen plants with tap water containing $0.01 \%$ ( $\mathrm{vol} / \mathrm{vol}$ ) Tween 80 ; the fungicide program as applied by the grower in his commercial growing system (described below); conidial suspension of G. roseum; and conidial suspension of $U$. atrum. In the second experiment, the fifth treatment consisted of spraying conidial suspensions of $U$. atrum with increased time intervals between applications.

In the first experiment, the water control and the conidial suspensions were applied five times when plants were 133, 153, 174, 189, and 205 days old. The fungicide program consisted of five applications of three different fungicides sprayed in the following rotation: Euparene M (1 $\mathrm{g} \mathrm{liter}^{-1}$, tolylfluanid at $500 \mathrm{~g}$ a.i. per $\mathrm{kg}$; Bayer AG, Leverkusen, Germany), Sporgon (1 g liter ${ }^{-1}$, prochloraz-manganese at $450 \mathrm{~g}$ a.i. per liter; Schering AG, Berlin), Euparene M, Sporgon, and Rovral Aquaflo ( $2 \mathrm{ml} \mathrm{liter}^{-1}$, iprodione at $500 \mathrm{~g}$ a.i. per liter; Rhône-Poulenc Agrochimie, Lyon, France), when plants were 112, 133, 153, 174, and 200 days old. Vertimec ( $0.5 \mathrm{ml} \mathrm{liter}^{-1}$, abamectin at $18 \mathrm{~g}$ a.i. per liter; MSD Agvet, Haarlem, the Netherlands) was sprayed three times during the experiment for thrips and mite control when plants were approximately 120, 160, and 200 days old.

In the second experiment, the water control and the conidial suspensions were applied nine times, when plants were 109, 130, $151,166,179,193,207,221$, and 236 days old. In the fifth treatment, $U$. atrum was applied only five times, when plants were 109 , 151, 179, 207, 236 days old. During the second experiment, the fungicide program consisted of five applications of four different fungicides sprayed in the following rotation: Daconil $\left(1 \mathrm{ml} \mathrm{liter}^{-1}\right.$, chlorothalonil at $500 \mathrm{~g}$ a.i. per liter; Schering AG), Euparene M, Sporgon, Rovral Aquaflo, and Rovral Aquaflo, when plants were 84, 106, 130, 160, and 225 days old. Control of thrips, mites, and Lepidoptera larvae was achieved by applying Vertimec (abamectin), Aseptacarex $\left(0.7 \mathrm{ml} \mathrm{liter}^{-1}\right.$, pyridaben at $157 \mathrm{~g} \mathrm{liter}^{-1}$; Aseptafabriek, Delft, the Netherlands), Mesurol (1 ml liter ${ }^{-1}$, methiocarb at $500 \mathrm{~g} \mathrm{liter}^{-1}$; Bayer AG, Leverkusen, Germany), Vydate (3 $\mathrm{ml} \mathrm{liter}^{-1}$, oxamyl at $100 \mathrm{~g} \mathrm{liter}^{-1}$; Dupont de Nemours, Wilmington, DE), and Luxan Permethrin (0.4 ml liter ${ }^{-1}$, permethrin at 
$250 \mathrm{~g} \mathrm{liter}^{-1}$; Luxan, Elst, the Netherlands) in rotation at intervals of approximately 40 days.

Because commercial crops were growing in the greenhouse, heavily infested plants were removed from the experiments to lower the inoculum density when plants were 205 (experiment 1) and 236 days old (experiment 2).

Application technique. Water and conidial suspensions were applied with a propane-operated sprayer (AZO, Ede, the Netherlands) at $250 \mathrm{kPa}$. Fungicides were applied with a motor-operated sprayer (EP55; Empas, Veenendaal, the Netherlands) at $400 \mathrm{kPa}$. During spraying, a polystyrene shield was placed around each treatment to prevent drift to neighboring plants. Each plant was sprayed individually until runoff. At the beginning of the experiments, plant canopies were open so that all leaf surfaces, petioles, and the tuber could easily be reached. Later, when plant canopies became dense, plants were sprayed on the canopy, but the spray nozzle also was put inside the canopy of each individual plant so as to reach plant surfaces shielded under the dense canopy such as the surfaces of older leaves, petioles, and the tuber. Treatment of individual plants is the standard method of fungicide applications.

Assessments. In both experiments, disease was assessed on each day that the antagonists were applied, and a final assessment was made 2 weeks after the last antagonist application, when plants were 219 (experiment 1) and 248 (experiment 2) days old.

The following parameters were assessed nondestructively in the greenhouse for each plant at each assessment date: the proportion of the area (ranging from $>0$ to 1 at intervals of 0.1 ) covered with conidiophores of the pathogen was estimated separately for each leaf blade and petiole with sporulation of $B$. cinerea. Because areas with conidiophores of $B$. cinerea varied from sparse to complete (maximal density) coverage, the intensity of sporulation of $B$. cinerea also was estimated for each single area with sporulating $B$. cinerea, using a relative scale from $>0$ to 1 (sparse sporulation to complete coverage with conidiophores) at intervals of 0.1 . The area of leaf blades and the length of petioles were not recorded.

The following parameters were calculated from the data obtained: the percentage of plants with symptoms of $B$. cinerea (disease incidence), the number of petioles per plant with symptoms of $B$. cinerea (disease severity), the estimated equivalent number of leaf blades with $B$. cinerea sporulation (spore-producing leaf area [SPLA]), the estimated equivalent number of leaf blades with $B$. cinerea sporulation corrected for sporulation intensity (spore-producing leaf area corrected for intensity [SPLACI]), the estimated equivalent number of petioles with $B$. cinerea sporulation (spore-producing petiole area [SPPA]), and the estimated equivalent number of petioles with $B$. cinerea sporulation corrected for sporulation intensity (spore-producing petiole area corrected for intensity [SPPACI]).

Because the size of assessed leaves was not measured, areas with sporulation of $B$. cinerea were not expressed in their absolute size; instead, SPLA and SPLACI represent the equivalent number of leaf blade surfaces per plant fully covered with sporulation. The formulas used for calculation were

$$
\text { SPLA }=\frac{\sum_{i=1}^{n} \sum_{j=1}^{m_{i}} p_{i j}}{n} \quad \text { (1) } \quad \text { SPLACI }=\frac{\sum_{i=1}^{n} \sum_{j=1}^{m_{i}} w_{i j} p_{i j}}{n}
$$

in which $i=$ number of plant, $i=1 \ldots n ; m_{i}=$ number of diseased leaves of plant $i ; p_{i j}=$ proportion of $j$ th leaf blade of plant $i$ covered by conidiophores of $B$. cinerea; and $w_{i j}=$ weight $\left(0<w_{i j} \ldots 1\right)$ for intensity of sporulation of $B$. cinerea on the $i j$ th leaf blade.

Data on $B$. cinerea sporulation on petioles were produced in the same way. For statistical analysis, the mean values of the assessed parameters for the 25 plants per plot (experiment 1) or the 24 plants per plot (experiment 2) were used.

Monitoring of fungicide resistance. $B$. cinerea was isolated from diseased cyclamen plants outside the experimental plot during the second experiment at three sampling dates (when plants were 207, 221, and 236 days old). These plants were growing in the same greenhouse and had the same fungicide treatments as the fungicide-treated plants of the experiment. For isolation, five bulk samples of B. cinerea conidia from one leaf of each of five plants were collected at each sampling date using a sterile wet cotton plug, which was subsequently streaked onto a petri dish containing potato dextrose agar (4 g of potato extract, $20 \mathrm{~g}$ of glucose, $15 \mathrm{~g}$ of agar, and 1 liter of tap water) amended with $10 \mu \mathrm{g}$ of tetracycline per $\mathrm{ml}$ and $100 \mu \mathrm{g}$ of streptomycin per ml. Plates were incubated for 6 days at $20^{\circ} \mathrm{C}$, newly formed conidia of $\mathrm{B}$. cinerea were transferred to petri dishes containing $15 \mathrm{ml}$ of malt extract agar (1 $\mathrm{g}$ of malt extract, $15 \mathrm{~g}$ of agar, and 1 liter of tap water), and the dishes were incubated for 4 to 5 days at $20^{\circ} \mathrm{C}$. Agar discs $(5 \mathrm{~mm})$ from the edges of the growing colonies were placed in the center of petri dishes each containing the same medium but amended with either chlorothalonil $\left(100 \mu \mathrm{g} \mathrm{ml}^{-1}\right)$, tolylfluanid $\left(10 \mu \mathrm{g} \mathrm{ml}^{-1}\right)$, iprodione $\left(10 \mu \mathrm{g} \mathrm{ml}^{-1}\right)$, or prochloraz-manganese $\left(1 \mu \mathrm{g} \mathrm{ml}^{-1}\right)$. Malt extract agar not amended with fungicide served as controls. There were five replications of each $B$. cinerea population for each of the media. For each colony that developed on the medium, two crossed diameters were measured after 4 and 10 days, and the radial growth rate per $24 \mathrm{~h}$ was calculated.

At the fungicide concentrations used in this study, the mycelial growth of five wild strains of $B$. cinerea from the collection of our institute was completely suppressed in preliminary experiments, but these strains had shown some growth at a 10-fold lower concentration of each fungicide. Two of these strains were used as references during the three assessments of $B$. cinerea populations obtained from the commercial greenhouse.

Survival of $\boldsymbol{U}$. atrum conidia on green cyclamen leaves and competitive colonization of senesced leaves by $B$. cinerea and $\boldsymbol{U}$. atrum. Fifty 20 -week-old potted cyclamen plants (cv. Super Serie) with approximately 15 leaves per plant were grown in an experimental greenhouse at $20 \pm 3^{\circ} \mathrm{C}$ and $65 \pm 20 \% \mathrm{RH}$. Pots were placed on a mat and water was supplied via the mat so that leaves were not wetted. The petioles of fully developed leaves were labeled with colored, plastic-coated iron rings. Treatments consisted of five plants sprayed with either a conidial suspension of $U$. atrum $385\left(1 \times 10^{6}\right.$ conidia per $\left.\mathrm{ml}\right)$ prepared as described above, or tap water containing $0.01 \%$ Tween 80 . The two treatments were arranged in a randomized complete block design, with each treatment replicated five times, and the experiment was repeated once.

Two or three labeled leaves (experiment 1 and 2, respectively) per sampling date per replicate were arbitrarily selected from the five plants of each replicate. Sampling dates were 0, 2, 4, 7, 10, $14,21,28,42,56$, and 70 days after spraying. Sampled leaves were healthy and without symptoms of $B$. cinerea during the experiment, but $B$. cinerea developed on senesced leaves of the plants. At each sampling date, one of the sampled leaves was cut longitudinally into two pieces. On one half, the density of conidia and the percentage of germinated conidia of $U$. atrum were determined. The other half was incubated at $24^{\circ} \mathrm{C}$ for $8 \mathrm{~h}$ in the dark in a moist chamber consisting of petri dishes $(55 \mathrm{~mm})$ with two moistened filter papers $(50 \mathrm{~mm})$ on the bottom and one in the lid to estimate the percentage of conidia of $U$. atrum that lost their ability to germinate.

Conidial density on the upper leaf surface was determined using a microscope at a magnification of $\times 100$. Each half-leaf was divided into 10 equally sized sections, and the conidial density was determined in the center of each section by counting the number of conidia laying within a grid representing $1 \mathrm{~mm}^{2}$. The average number of $U$. atrum conidia per square centimeter of leaf surface was calculated for each leaf.

To determine germination of conidia of $U$. atrum on the leaf surface directly after sampling or after additional incubation in a moist chamber, a droplet of $0.01 \%$ calcofluor white (Fluorescent Brightener 28, F-6259, Sigma Chemical Co., St. Louis; $0.01 \%$ $\mathrm{wt} / \mathrm{vol}$ in $1 \mathrm{M}$ Tris- $\mathrm{HCl}$ buffer, $\mathrm{pH} 8$ ) was added to the leaf surface, and the surface was inspected at a magnification of $\times 100$ 
under a fluorescence microscope (Axioscope with filter 05; Carl Zeiss, Inc., Oberkochen, Germany) using a blue-violet (395 to 440 nm) light source. Per half-leaf, 100 arbitrarily chosen, nonclustered conidia were assessed. Conidia were counted as germinated when germ tube length was at least half of the shortest axis of the ellipsoidal conidium.

The remaining one or two leaves per replicate (experiment 1 or 2 , respectively) were placed in an open petri dish $(55 \mathrm{~mm})$ on two dry filter papers $(50 \mathrm{~mm})$ for 21 days (experiment 1$)$ or 28 to 42 days (experiment 2). Petri dishes were arranged in blocks as described above for plants. After the detached leaves in the petri dishes had senesced (characterized by the loss of turgor and a yellow or brown color) during a period of 3, 4, or 6 weeks in the experimental greenhouse, $0.75 \mathrm{ml}$ of tap water were added to each petri dish and the closed dishes were transferred to an incubator. Leaves were incubated at $18^{\circ} \mathrm{C}$ in the dark. After 14 days, the coverage of the upper surface of the leaves with conidiophores of B. cinerea, $U$. atrum, and other fungi was estimated in classes ranging between 0 and 1 (i.e., $0,0.01,0.05,0.1,0.2, \ldots, 0.8,0.9,0.95,0.99$, 1) using a stereomicroscope with 10 to $40 \times$ magnification (14). In the first experiment, in many cases, leaves were not senescent at the assessment date and no fungi developed. Data from such leaves were excluded from the analysis. Data from three sampling dates, based on at least one leaf per replicate, were further analyzed. In the second experiment, detached leaves were left in the greenhouse for 28 days. Thereafter, senesced leaves were incubated in a moist chamber. Leaves without symptoms of senescence were left in the greenhouse for another 14 days. At assessment dates, 14 days after incubation in a moist chamber, all leaves were necrotic.

Statistics. Linear logistic regression was employed to explain the number of diseased plants (disease incidence) in response to the classifying variables: replicate and treatment. The model assumes that the variance of the data is from a distribution more variable than the binomial and can be adequately described by variance proportional to binomial variance. Log-linear regression models with the same classifying variables and variance assumed to be proportional to Poisson variance were fitted to the data on the number of diseased petioles (disease severity), SPLA, SPLACI, SPPA, and SPPACI. Models were fitted to the data using the method of quasilikelihood (18). Overall effects of replicate and treatment were assessed using $F$ tests for the ratio of the mean deviance for the particular effect and the mean residual deviance. In case $F$ tests were significant, treatment means on the logit or log-scale were separated using $t$ tests $(P<0.05)$, corresponding to least significant difference (LSD) tests for normal distributed data, because standard errors of differences are not constant for logistic and loglinear regressions. Differences between means of the control treatments and the other treatments were assessed one-sided, differences between means of treatments with antagonists or fungicides were assessed two-sided. Analysis of variance (ANOVA) was employed on log-transformed counts of $U$. atrum conidia per square centimeter and on arcsine-transformed data on sporulation of $B$. cinerea, and LSD tests were used to separate treatment means. All analyses were performed with the Genstat 5 program (Nummerical Algorithmus Group Inc., Oxford).

\section{RESULTS}

Disease control under commercial growing conditions. In the first experiment, no sporulation of $B$. cinerea was found at the beginning of the experiment. Sporulation initially was observed on dead leaf tissue of 153-day-old plants. The estimated B. cinerea SPLACI increased with time in all treatments (Fig. 1A). When plants were near marketable age at 205 days, more than 0.8 leaves per plant of the control treatment were completely covered with sporulating $B$. cinerea. SPLACI was reduced significantly to 0.15 by the application of $U$. atrum or the fungicides. Disease incidence increased with time, and more than $80 \%$ of the water- treated plants showed symptoms of $B$. cinerea at a plant age of 205 days (Fig. 1B). Treatments with $U$. atrum or fungicides resulted in significant disease suppression with disease incidences of 40 and $46 \%$, respectively. The number of diseased petioles per plant increased during the experiment in all treatments, but was significantly reduced by treatment with $U$. atrum (0.9) or fungicides (0.7) as compared with the control (3.5) at a plant age of 205 days (Fig. 1C). On average, approximately 1.8 petioles per plant treated with $G$. roseum were infected.

Several heavily infected plants of the different treatments were removed from the greenhouse at a plant age of 205 days to reduce
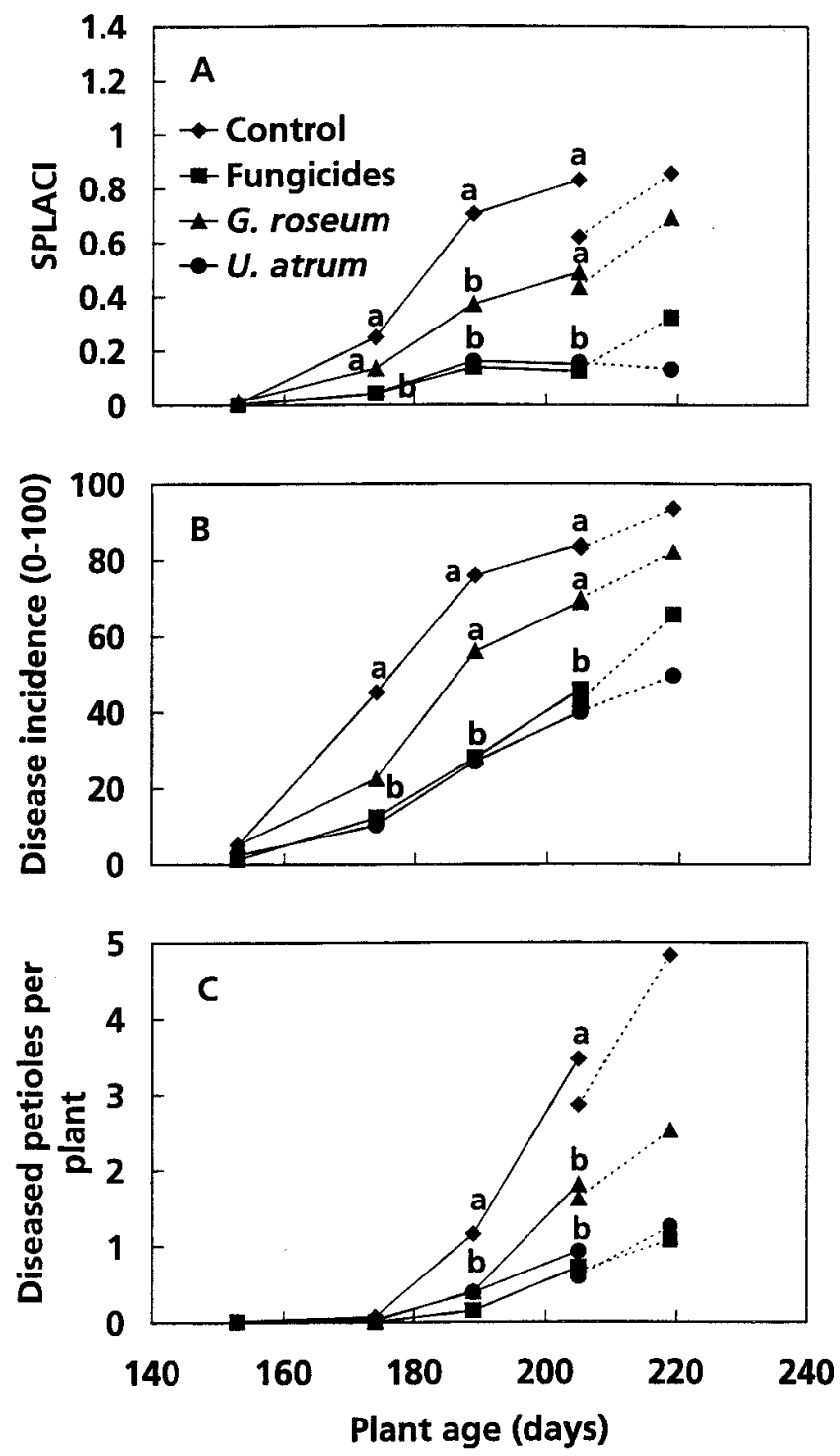

Fig. 1. Effect of treatments with Ulocladium atrum, Gliocladium roseum, and a fungicide program on $\mathbf{A}$, spore-producing leaf area corrected for intensity (SPLACI); B, disease incidence; and C, disease severity of Botrytis cinerea on cyclamen plants cv. Super Serie under commercial growing conditions. Conidial suspensions of $U$. atrum $\left(1 \times 10^{6}\right.$ conidia per ml $)$ and $G$. roseum $(2 \times$ $10^{6}$ conidia per $\mathrm{ml}$ ) were applied at a plant age of $133,153,174,189$, and 205 days. Tolylfluanid, prochloraz-manganese, tolylfluanid, prochloraz-manganese, and iprodione were applied in rotation when plants were 112, 133, 153, 174 , and 200 days old. SPLACI is defined as the estimated equivalent number of leaf blades per plant completely covered with conidiophores of $B$. cinerea; disease incidence is defined as the percentage of plants with symptoms of $B$. cinerea; and disease severity is defined as the average number of petioles with symptoms of $B$. cinerea per plant. Dotted lines represent remaining plants after heavily diseased plants had been removed at a plant age of 205 days. Twenty-five plants of each of four replicates were assessed. Values of the same assessment date with a common letter do not differ significantly $(P<0.05)$ according to logistic or log-linear regression followed by $t$ tests. 
the inoculum density for neighboring commercially grown crops. SPLACI, disease incidence, and disease severity of the remaining plants of the control treatment increased during the subsequent 14 days, but SPLACI and disease severity increased more slowly for plants treated with $U$. atrum (Fig. 1A to C).

In the second experiment, treatments were started with younger plants (plant age of 109 days) that did not show symptoms caused by $B$. cinerea. $B$. cinerea sporulation first occurred at a plant age
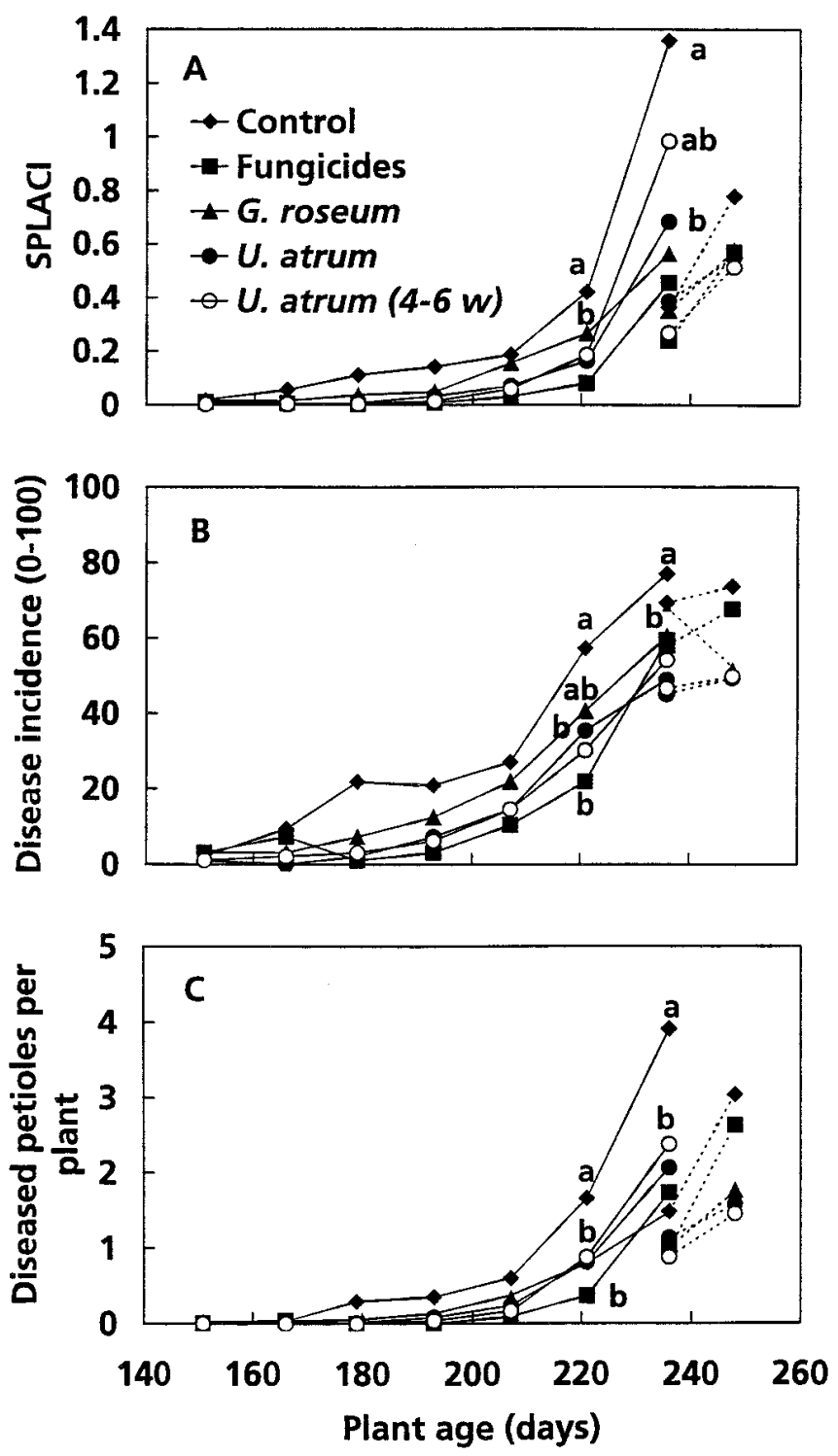

Fig. 2. Effect of treatments with Ulocladium atrum, Gliocladium roseum, and a fungicide program on $\mathbf{A}$, spore-producing leaf area corrected for intensity (SPLACI); B, disease incidence; and $\mathbf{C}$, disease severity of Botrytis cinerea on cyclamen plants cv. Super Serie under commercial growing conditions. Conidial suspensions of $U$. atrum $\left(1 \times 10^{6}\right.$ conidia per $\left.\mathrm{ml}\right)$ and G. roseum $(1 \times$ $10^{7}$ conidia per ml) were applied at intervals of 2 to 3 weeks at plant ages of $109,130,151,166,179,193,207,221$, and 236 days. In an additional treatment, $U$. atrum was applied at intervals of 4 to 6 weeks (4-6 w) at plant ages of $109,151,179,207$, and 236 days. Chlorothalonil, tolylfluanid, prochloraz-manganese, iprodione, and iprodione were applied in rotation when plants were $84,106,130,160$, and 225 days old. SPLACI is defined as the estimated equivalent number of leaf blades per plant completely covered with conidiophores of $B$. cinerea; disease incidence is defined as the percentage of plants with symptoms of $B$. cinerea; and disease severity is defined as the average number of petioles with symptoms of $B$. cinerea per plant. Dotted lines represent remaining plants after heavily diseased plants had been removed at a plant age of 236 days. Twenty-four plants of each of four replicates were assessed. Values of the same assessment date with a common letter do not differ significantly $(P<0.05)$ according to logistic or log-linear regression followed by $t$ tests. of 151 days. During the last month of experiment 2, disease development was more rapid than in the first experiment (Fig. 2). When plants were close to marketability (plant age of 236 days), approximately 1.4 leaves per plant of the water control were completely covered with $B$. cinerea (Fig. 2A). SPLACI was significantly reduced to below 0.7 leaves per plant by the application of $U$. atrum (applied at intervals as in experiment 1), G. roseum (applied at a 5× higher dose than in experiment 1 ), and the fungicides. $U$. atrum applied at increased intervals significantly reduced SPLACI assessed at a plant age of 179, 193, 207, and 221 days, but not of 236 days. Disease incidence in the treatments with antagonists or fungicides was significantly reduced to 50 to $60 \%$, as compared with $77 \%$ in the control treatment at a plant age of 236 days (Fig. 2B). Disease severity based on diseased petioles per plant had the same pattern (Fig. 2C). Antagonist and fungicide treatments significantly reduced the number of diseased petioles from 3.9 in the water control to 1.5 to 2.3 , with no significant differences between these treatments. After heavily diseased plants were removed when plants were 236 days old, the disease severity of the remaining control plants increased from 1.5 to 3.0 during the next 14 days. For $U$. atrumtreated plants, the disease severity increased from 1.1 to 1.6 (regular application intervals) and from 0.9 to 1.5 (increased application intervals), respectively.

For both experiments, the different treatments had similar effects on sporulation of B. cinerea on both leaf blades (SPLA, SPLACI) and petioles (SPPA, SPPACI) as on disease severity (Figs. 1 and 2, Table 1). Significant block effects, at least partly to be attributed to possible differences in resistance against $B$. cinerea of lines with different flower color, were found for several assessment dates during experiment 2 but not during experiment 1 (e.g., disease severity was twice as high in one block, consisting of plants with wine

TABLE 1. Effect of Ulocladium atrum, Gliocladium roseum, and fungicides on the spore-producing leaf area (SPLA), spore-producing petiole area (SPPA), and spore-producing petiole area corrected for intensity (SPPACI ${ }^{\mathrm{x}}$ of cyclamen plants cv. Super Serie grown in a commercial greenhouse

\begin{tabular}{llll}
\hline Treatment $^{\mathrm{y}}$ & SPLA & SPPA & SPPACI \\
\hline Experiment 1 & $1.31 \mathrm{a}^{\mathrm{z}}$ & $2.82 \mathrm{a}$ & $1.73 \mathrm{a}$ \\
$\quad$ Control & $0.25 \mathrm{~b}$ & $0.46 \mathrm{c}$ & $0.23 \mathrm{~b}$ \\
Fungicides & $0.76 \mathrm{a}$ & $1.27 \mathrm{~b}$ & $0.78 \mathrm{~b}$ \\
G. roseum & $0.25 \mathrm{~b}$ & $1.03 \mathrm{bc}$ & $0.63 \mathrm{~b}$ \\
$\quad$ U. atrum & & & \\
Experiment 2 & $1.86 \mathrm{a}$ & $3.01 \mathrm{a}$ & $2.08 \mathrm{a}$ \\
$\quad$ Control & $0.83 \mathrm{~b}$ & $1.33 \mathrm{bc}$ & $0.77 \mathrm{bc}$ \\
Fungicides & $0.97 \mathrm{~b}$ & $0.90 \mathrm{c}$ & $0.59 \mathrm{c}$ \\
$\quad$ G. roseum & $1.05 \mathrm{~b}$ & $1.75 \mathrm{bc}$ & $0.88 \mathrm{bc}$ \\
U. atrum (every 2 to 3 weeks) & $1.46 \mathrm{ab}$ & $2.02 \mathrm{ab}$ & $1.38 \mathrm{ab}$ \\
$\quad$ U. atrum (every 4 to 6 weeks) &
\end{tabular}

x SPLA is defined as the estimated equivalent number of leaf blades per plant with conidiophores of Botrytis cinerea; SPPA is defined as the estimated equivalent number of petioles per plant with conidiophores of $B$. cinerea; and SPPACI is defined as the estimated equivalent number of petioles per plant completely covered with conidiophores of $B$. cinerea. Plant age at assessment date was 205 days (experiment 1) and 236 days (experiment 2 ).

y In experiment 1 , conidial suspensions of $U$. atrum $\left(1 \times 10^{6}\right.$ conidia per ml $)$ and G. roseum $\left(2 \times 10^{6}\right.$ conidia per $\left.\mathrm{ml}\right)$ were applied at a plant age of 133 , $153,174,189$, and 205 days. The fungicides tolylfluanid, prochloraz-manganese, tolylfluanid, prochloraz-manganese, and iprodione were applied in rotation when plants were $112,133,153,174$, and 200 days old. In experiment 2, conidial suspensions of $U$. atrum $\left(1 \times 10^{6}\right.$ conidia per $\left.\mathrm{ml}\right)$ and G. roseum $\left(1 \times 10^{7}\right.$ conidia per $\left.\mathrm{ml}\right)$ were applied at intervals of 2 to 3 weeks at a plant age of 109, 130,151, 166, 179, 193, 207, 221, and 236 days. In an additional treatment, $U$. atrum was applied at intervals of 4 to 6 weeks at a plant age of 109, 151, 179, 207, and 236 days. Chlorothalonil, tolylfluanid, prochloraz-manganese, iprodione, and iprodione were applied in rotation when plants were $84,106,130,160$, and 225 days old.

${ }^{\mathrm{z}}$ In the two experiments, 25 and 24 plants of each of four replicates were assessed. Means in the same column and the same experiment with a common letter do not differ significantly $(P<0.05)$ according to log-linear regression followed by $t$ tests. 
red flowers, than in the three other blocks, consisting of plants with pink, white with red heart, or lilac flowers, respectively).

Occasionally, epiphytic colonies of $U$. atrum were found on the lower side of leaves where humidity in the canopy allowed epiphytic growth. Such colonies could be wiped off without any sign of leaf damage underneath the colony.

Fungicide resistance. From the $15 \mathrm{~B}$. cinerea isolates obtained from the commercial greenhouse, no mycelial growth was found on prochloraz-manganese amended agar, while two isolates grew on tolylfluanid-amended agar and nine on iprodione-amended agar. Growth of those isolates showing mycelium development on agar was reduced on average by $90 \%$ for tolylfluanid and $75 \%$ for iprodione. All 15 isolates grew on the chlorothalonil-amended agar, but growth was reduced by $90 \%$.

With one exception, the two reference strains of $B$. cinerea from our institute did not grow on agar containing prochloraz-manganese, iprodione, or tolylfluanid at the concentrations given above. One isolate grew in one experiment on tolylfluanid-amended agar; its growth was reduced by $90 \%$ as compared with the control. On agar amended with chlorothalonil, growth was reduced 80 to $100 \%$.

Survival of conidia of $\boldsymbol{U}$. atrum on cyclamen leaves. On green cyclamen leaves treated with conidial suspensions of $U$. atrum $\left(1 \times 10^{6}\right.$ conidia per $\left.\mathrm{ml}\right), 3,880$ and 4,070 conidia per $\mathrm{cm}^{2}$ of leaf were found directly after spraying for each experiment (Fig. 3). In the first experiment, the number of conidia per square centimeter of leaf remained stable for 8 weeks, but at day 70 significantly $(P<0.05)$ fewer conidia were found $\left(1,120\right.$ conidia per $\mathrm{cm}^{2}$ of leaf). In the second experiment, the conidial density was stable until the end of the experiment and was 3,165 at day 70. On leaves of the water control, conidia of $U$. atrum were found only on rare occasions in both experiments. The mean conidial density for all assessment dates was below 0.03 conidia per $\mathrm{cm}^{2}$ of leaf.

The percentage of germinated conidia of $U$. atrum on the healthy cyclamen leaves in the greenhouse remained below $12 \%$ during the first experiment (Fig. 4). During the second experiment, the percentage of germinated conidia increased after day 7 from 0.4 to $10 \%$. Thereafter, percentages of germinated conidia ranged between 10 and $30 \%$, but there was no trend for a further increase of the germination over time.

After incubation of leaf samples in moist chambers, the percentage of germinated conidia of $U$. atrum was consistently high during both experiments; 80 and $86 \%$ at the beginning and 81 and $64 \%$ at the end of experiments 1 and 2, respectively.

Competitive colonization of dead cyclamen leaves by $B$. cinerea and $\boldsymbol{U}$. atrum. In experiment $1, B$. cinerea sporulation was significantly lower at the three analyzed sampling dates on $U$. atrum-treated leaves than on leaves of the water control. At sam-

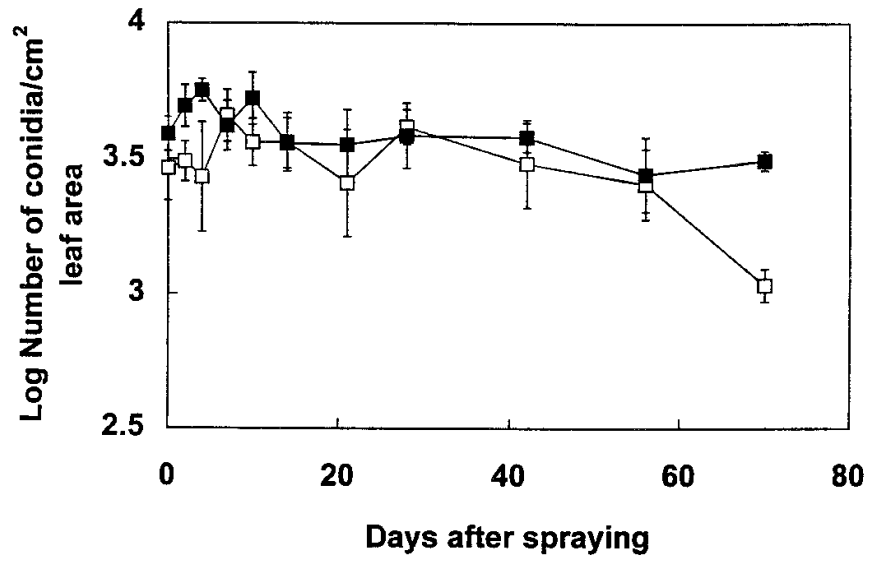

Fig. 3. Density of conidia of Ulocladium atrum on green cyclamen leaves under greenhouse conditions $(\square=$ experiment $1 ; \boldsymbol{\square}=$ experiment 2 ). Leaves were sprayed with a conidial suspension $\left(1 \times 10^{6}\right.$ conidia per ml $)$ at day 0 . Means \pm standard errors of the mean of five leaves (replicates) per assessment date. pling days 42,56 , and 70 , the coverage of the leaf area with sporulating $B$. cinerea was 42,58 , and $33 \%$ on the water-treated leaves but 12,0 , and $10 \%$ on $U$. atrum-treated leaves, respectively. In the second experiment, no difference in fungal colonization was found for leaves that had been left senescing for 28 or 42 days in the greenhouse, and the data for such leaves were pooled for data analysis. Leaves were highly contaminated by $B$. cinerea inoculum produced on infected cyclamen plants present in the greenhouse, and sporulation of the pathogen was found on $84 \%$ of the area of leaves from the water control (mean of all sampling dates) (Fig. 5). B. cinerea sporulation was significantly reduced by the treatment with $U$. atrum compared with the water control for all sampling dates. On average, $19 \%$ of the leaf area was covered with $B$. cinerea sporulation. The reduction in sporulation of $B$. cinerea by $U$. atrum ranged from $95 \%$ on leaves removed at day 0 to $56 \%$ on leaves sampled at day 70 after application of $U$. atrum conidia.

\section{DISCUSSION}

In our study, the regular application of conidial suspensions of $U$. atrum $\left(1 \times 10^{6}\right.$ conidia per $\left.\mathrm{ml}\right)$ suppressed the incidence and

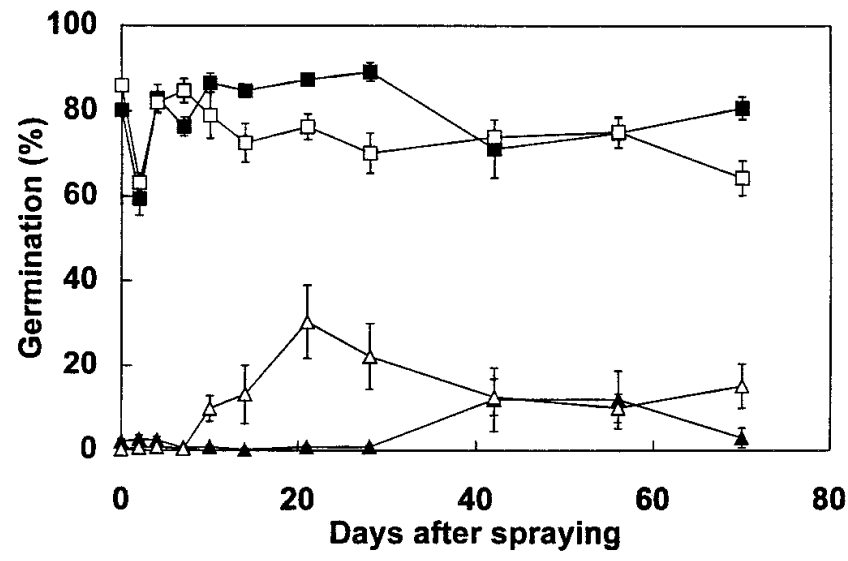

Fig. 4. Germination of conidia of Ulocladium atrum on green cyclamen leaves under greenhouse conditions directly after sampling $(\mathbf{\Delta}=$ experiment $1 ; \Delta=$ experiment 2) or after incubation in moist chamber at $24^{\circ} \mathrm{C}$ for $8 \mathrm{~h}(\boldsymbol{\square}=$ experiment $1 ; \square=$ experiment 2 ). Leaves were sprayed with a conidial suspension $\left(1 \times 10^{6}\right.$ conidia per $\left.\mathrm{ml}\right)$ at day 0 . Means \pm standard errors of the mean of 100 conidia on each of five leaves (replicates) per assessment date.

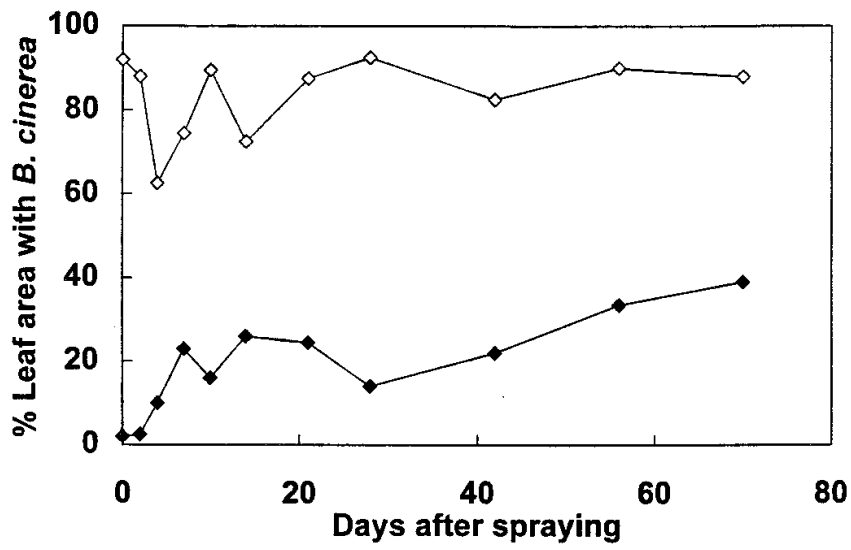

Fig. 5. Percentage of leaf area with Botrytis cinerea sporulation on necrotic cyclamen leaves. Leaves were sprayed with a conidial suspension of Ulocladium atrum $\left(1 \times 10^{6}\right.$ conidia per $\left.\mathrm{ml}\right)(\diamond)$ or with water $(\diamond)$. Healthy green leaves of plants in an experimental greenhouse were treated at day 0 , detached from plants at the indicated sampling date, allowed to senesce during 28 to 42 days in the greenhouse, and subsequently incubated in a moist chamber $\left(14\right.$ days, $\left.18^{\circ} \mathrm{C}\right)$. The two treatments differed significantly $(P<0.05)$ at all assessment dates according to least significant difference tests. 
severity of B. cinerea rot in cyclamen under commercial growing conditions. Increasing the intervals between applications of the antagonist from 2 to 4 weeks in the second experiment resulted in similar levels of control on the basis of measurements of disease incidence and disease severity. Regular applications of conidial suspensions of $G$. roseum $\left(2 \times 10^{6}\right.$ conidia per $\left.\mathrm{ml}\right)$ suppressed the disease half as effectively as $U$. atrum (experiment 1 ) and were similar to $U$. atrum treatments when applied with $1 \times 10^{7}$ conidia per ml (experiment 2). Such antagonist applications provided control at levels similar to those of the standard fungicide program used by the grower.

Monitoring for fungicide resistance amongst the $B$. cinerea populations in the commercial greenhouse indicated that all evaluated populations were sensitive to prochloraz, tolylfluanid, iprodione, and chlorothalonil. From these observations it can be concluded that the fungicide program as applied in the commercial greenhouse was adequate to control $B$. cinerea.

Both antagonists, U. atrum and G. roseum, were selected for their potential to suppress sporulation of Botrytis spp. on necrotic plant tissues (16). In the current experiments, it is likely that the colonization of the senescing leaves within the cyclamen canopy by the antagonists led to reduced saprophytic development by $B$. cinerea on such substrates, thus resulting in lower inoculum potential towards adjacent healthy petioles and leaves. Such a microbial exclusion of $B$. cinerea from naturally senescing leaves may be an efficient means for disease control in cyclamen and other crops in which naturally occurring senesced leaf tissues play an important role in the buildup of Botrytis-inoculum (e.g., in geranium stock plants) (7). The exploitation of microbial interactions in necrotic tissues to prevent pathogen colonization and sporulation has the advantage of a long period of interaction between pathogen and antagonist $(4,12)$.

The colonization and the subsequent sporulation of $B$. cinerea on necrotic leaf tissue results not only in a high inoculum potential within the canopy of individual plants, but also an increase in the spore load within the greenhouse. In our experiments, plots were small and were not separated by disease-free buffers, whereas other crops, also affected by the pathogen, were present in the greenhouse. Suppression of sporulation of Botrytis spp. resulting in a lower spore load within a crop and in a slower disease progression was demonstrated by Köhl et al. (13) for onion leaf spot under field conditions. It is likely that microbial suppression of sporulation can be exploited for a similar disease control within a greenhouse when all potential sources of spore production within a greenhouse compartment are treated. The application of antagonists such as $U$. atrum may then affect the spread of the disease within the canopy of the individual plant, as well as between plants.

Further research is needed toward an increase of the interval between applications of the antagonists. In our study, we made a first attempt by spraying $U$. atrum at 4-week intervals. Our studies in the experimental greenhouse demonstrated that propagules of this antagonist have the potential to survive on the surface of green leaves for at least 70 days under dry conditions. When such green leaves senesced 70 days after the antagonist application and thus became available as substrate for saprophytic colonization by both $B$. cinerea and $U$. atrum, propagules of the antagonist still had the potential to compete successfully with the pathogen. Because the amount of $B$. cinerea inoculum on the leaves was not standardized during the experiments, the amount of suppression obtained with antagonist propagules exposed to greenhouse conditions for different time periods cannot directly be compared. Experiments under commercial growing conditions with antagonist applications only to green leaves in an early growth stage of the cyclamen crop are needed, and may provide information as to whether propagule survival of $U$. atrum is sufficient for a persistent disease control during cyclamen production. Such early applications will reduce labor costs, especially because an overhead treatment of the plants will be sufficient to reach all surfaces. An individual treatment of the heart of the plant, as is necessary for fungicide or antagonist application during the later developmental stage of the plants, then will not be necessary. An early application of $U$. atrum on plants before the dense canopy is formed also reduces the risk of black spots from dried droplets of the conidial suspension on marketable plants as found when plants are sprayed a couple of weeks before marketing.

Applications of $G$. roseum $\left(1 \times 10^{7}\right.$ conidia per $\left.\mathrm{ml}\right)$ resulted in the same level of control as applications of $U$. atrum $\left(1 \times 10^{6}\right.$ conidia per $\mathrm{ml}$ ). Considering the small size of $G$. roseum conidia, the applied biomass does not exceed the applied biomass of $U$. atrum. Environmental factors such as temperature and water availability may have a differential effect on the performance of the two antagonists. G. roseum is more susceptible to interruptions of leaf wetness periods and less efficient against $B$. cinerea at temperatures below $21^{\circ} \mathrm{C}$ than is $U$. atrum (16, J. Köhl, unpublished data). This may explain the better control of $B$. cinerea sporulation by $U$. atrum than by a Gliocladium sp. under open field conditions (14). However, the microclimate within the canopy of a greenhousegrown potted plant differs from that in the open field. It can be assumed that, besides periods of free water availability, the water potential of dead leaves is high enough to allow fungal growth during longer time periods within the dense cyclamen canopy as compared with the open field (15). Because G. roseum showed strong antagonistic activity against $B$. aclada under continuously moist conditions even at a water potential of $-6.6 \mathrm{MPa}(15)$, this antagonist seems to be an attractive candidate for biological control of $B$. cinerea sporulation in greenhouse crops.

The key environmental factors (e.g., temperature and water availability) affecting the efficacy of an antagonist in the cyclamen system have to be identified. This knowledge will help to predict the performance of the antagonist under the various environmental conditions occurring in practice. Such a system should reduce the application frequencies of the antagonist and lead to a reliable and environmentally friendly control of $B$. cinerea in cyclamen and other ornamental crops.

\section{ACKNOWLEDGMENTS}

This study was partly financed by the Dutch Product Board for Horticulture. We thank P. Schoneveld and G. Zwiers from Schoneveld Twello B.V., Twello, the Netherlands, for providing greenhouse facilities and technical support; P. F. G. Vereijken for statistical data analysis; W. M. L. Molhoek and C. H. Lombaers-van der Plas for technical assistance; and N. J. Fokkema for fruitful and stimulating discussions.

\section{LITERATURE CITED}

1. Bollen, G. J. 1982. Fungicide resistance and microbial balance. Pages 161-176 in: Fungicide Resistance in Crop Protection. J. Dekker and S. G. Georgopoulos, eds. Pudoc Agricultural Publishing and Documentation, Wageningen, the Netherlands.

2. De Waard, M. A., Georgopoulos, S. G., Hollomon, D. W., Ihsii, H., Leroux, P., Ragsdale, N. N., and Schwinn, F. J. 1993. Chemical control of plant diseases: Problems and prospects. Annu. Rev. Phytopathol. 31: 403-421.

3. Elad, Y. 1996. Mechanisms involved in the biological control of Botrytis cinerea incited diseases. Eur. J. Plant Pathol. 102:719-732.

4. Fokkema, N. J. 1993. Opportunities and problems of control of foliar pathogens with micro-organisms. Pestic. Sci. 37:411-416.

5. Gullino, M. L. 1992. Chemical control of Botrytis spp. Pages 217-222 in: Recent Advances in Botrytis Research. K. Verhoeff, N. E. Malathrakis, and B. Williamson, eds. Pudoc Scientific Publishers, Wageningen, the Netherlands.

6. Hausbeck, M. K., and Pennypacker, S. P. 1991. Influence of grower activity on concentrations of airborne conidia of Botrytis cinerea among geranium cuttings. Plant Dis. 75:1236-1243.

7. Hausbeck, M. K., Pennypacker, S. P., and Stevenson, R. E. 1996. The effect of plastic mulch and forced heated air on Botrytis cinerea on geranium stock plants in a research greenhouse. Plant Dis. 80:170-173.

8. Henseler, K. 1981. Fungizide beeinträchtigen den Ertrag. Möglichkeiten der Botrytis-Bekämpfung bei Schnittcyclamen. Gartenbau Gartenwirtschaft $81: 382$. 
9. Iyozumi, H., Komagata, T., Hirayae, K., Tsuchiya, K., Hibi, T., and Akutsu, K. 1996. Biological control of cyclamen gray mould (Botrytis cinerea) by Serratia marcescens B2. Ann. Phytopathol. Soc. Jpn. 62:559-565.

10. Jacob, M. 1987. Bekämpfung bedeutender Schaderreger bei der Produktion von Cyclamen. Gartenbau 34:281-283.

11. Köhl, J., Bélanger, R. R., and Fokkema, N. J. 1997. Interaction of four antagonistic fungi with Botrytis aclada in dead onion leaves: A comparative microscopic and ultrastructural study. Phytopathology 87:634-642.

12. Köhl, J., and Fokkema, N. J. 1997. Strategies for biological control of necrotrophic fungal foliar pathogens. Pages 49-88 in: Plant-Microbe Interactions and Biological Control. G. J. Boland and L. D. Kuykendall, eds. Marcel Dekker, Inc., New York.

13. Köhl, J., Molhoek, W. M. L., van der Plas, C. H., and Fokkema, N. J. 1995. Suppression of sporulation of Botrytis spp. as a valid biocontrol strategy. Eur. J. Plant Pathol. 101:251-259.

14. Köhl, J., Molhoek, W. M. L., van der Plas, C. H., and Fokkema, N. J. 1995. Effect of Ulocladium atrum and other antagonists on sporulation of Botrytis cinerea on dead lily leaves exposed to field conditions. Phytopathology 85:393-401.

15. Köhl, J., van der Plas, C. H., Molhoek, W. M. L., and Fokkema, N. J. 1993. Drought tolerance as a major selection criterium for antagonists of Botrytis spp. Pages 169-171 in: Biological Control of Foliar and PostHarvest Diseases. N. J. Fokkema, J. Köhl and Y. Elad, eds. IOBC/WPRS
Bull. 16(11).

16. Köhl, J., van der Plas, C. H., Molhoek, W. M. L., and Fokkema, N. J. 1995. Effect of interrupted leaf wetness periods on suppression of sporulation of Botrytis allii and B. cinerea by antagonists on dead onion leaves. Eur. J. Plant Pathol. 101:627-637.

17. Lacroix, L., and Gouot, J. M. 1981. Étude en serre de la résistance de Botrytis cinerea à l'iprodione. Med. Fac. Landbouww. Rijksuniv. Gent 46:979-989.

18. McCullagh, P., and Nelder, J. A. 1989. Generalized Linear Models. 2nd ed. Chapman and Hall, London.

19. Pappas, A. C. 1982. Inadequate control of grey mould on cyclamen by dicarboximide fungicides in Greece. Z. Pflanzenkr. Pflanzenschutz 89: 52-58.

20. Reimherr, P. 1985. Atlas der Krankheiten und Schädlinge bei Cyclamen. Gartenbau Gartenwirtschaft 85:1780-1790.

21. Schlösser, E. 1978. Entwicklungsstadien von Alpenveilchenblättern (Cyclamen persicum)-Besiedlung durch Botrytis cinerea. Z. Pflanzenkr. Pflanzenschutz 85:179-185.

22. Sutton, J. C., Li, D.-W., Peng, G., Yu, H., Zhang, P., and ValdebenitoSanhueza, R. M. 1997. Gliocladium roseum, a versatile adversary of Botrytis cinerea in crops. Plant Dis. 81:316-328.

23. Van Dommelen, L., and Bollen, G. J. 1973. Antagonisms between benomyl-resistant fungi on cyclamen sprayed with benomyl. Acta Botanica Neerlandica 22:169-170. 